\begin{tabular}{|l|l|l|l|l|l|}
\hline J. Tek. Ling & Vol.11 & No.1 & Hal. 119 - 123 & Jakarta, Januari 2010 & ISSN 1441-318X \\
\hline
\end{tabular}

\title{
PENINGKATAN PRODUKTIVITAS LAHAN MELALUI PEMANFAATAN BIOMAS TANAMAN Flemengia congesta UNTUK BUDIDAYA TANAMAN JAGUNG DI DAERAH TRANSMIGRASI KURO TIDUR, BENGKULU
}

\author{
Daru Mulyono \\ Peneliti di Pusat Teknologi Produksi Pertanian \\ Badan Pengkajian dan Penerapan Teknologi
}

\begin{abstract}
The objective of the research is to know the effect of using biomass and combination between biomass and dolomit to the land fertility with regard to corn production. The research used Complete Randomized Design with One Way Analysis of Variance, Regression, and Correlation in order to know the effect of treatment to the land fertility. The research was carried out in Wonoharjo Village, Unit VIII Kuro Tidur Transmigration area, Bengkulu, during three planting seasons from 2003 to 2004. The results of the research showed that biomass from prunning of the hedgerows Flemengia congesta was significant to land fertility through improvement of nutrients availability, increasing $\mathrm{pH}$, decreasing availability of aluminium ( $\mathrm{Al})$. The effect of biomass treatment into the soil to a high of 5.0 ton/ha will increase average corn production from $22.256 \mathrm{kw} / \mathrm{ha}$ (dry grain) to $37.433 \mathrm{kw} / \mathrm{ha}$ or increase $68.19 \%$, whereas the effect of organic matter 5.0 ton/ha combined with dolomit 2.5 ton/ha will increase average corn production from $22.256 \mathrm{kw} / \mathrm{ha}$ to $47.611 \mathrm{kw} / \mathrm{ha}$ or increase $113.92 \%$. The effect of biomass 10.0 ton/ha combined with dolomit 2.5 ton/ha will increase average corn production from 22.256 $\mathrm{kw} / \mathrm{ha}$ to $50.789 \mathrm{kw} / \mathrm{ha}$ or increase $128.20 \%$.
\end{abstract}

Keywords: biomass, fence crop, corn

\section{PENDAHULUAN}

\subsection{Latar Belakang}

Daerah transmigrasi Kuro Tidur, Bengkulu sebagian besar tanahnya merupakan jenis Podzolik. Tanah ini pada umumnya kurang subur dengan ciri-ciri sebagai berikut: rendahnya $\mathrm{pH}$, miskin unsur hara (khususnya N, P, K, Ca, dan Mg), rendahnya kapasitas tukar kation (KTK), rendahnya kadar biomas, dan tingginya konsentrasi aluminium (Al) pada tingkat yang meracuni. ${ }^{2), 3)}$ Jenis tanah ini disamping mempunyai sifat dan ciri seperti tersebut di atas juga mempunyai lapisan atas yang subur tetapi sangat tipis. Biasanya setelah tanah ini dibuka untuk lahan pertanian akan

berakibat merosotnya kesuburan tanah karena adanya erosi yang disebabkan karena kemiringan tanah dan curah hujan yang tinggi. Untuk itu pemberian biomas akan dapat meningkatkan kesuburan tanah melalui: penyediaan unsur hara tanah, meningkatkan KTK, memperbaiki struktur tanah, dan memperbaiki sifat biologi tanah. 6),7)

Lahan di daerah transmigrasi Kuro Tidur, biasanya dipakai untuk budidaya tanaman jagung. Jagung merupakan bahan pangan pokok kedua setelah beras yang sangat penting artinya dalam memenuhi 
kebutuhan pangan masyarakat di daerah transmigrasi. Lebih jauh lagi, dalam skala nasional, peranan komoditas jagung dalam percaturan pangan saat ini menjadi semakin besar mengingat bahan pangan beras beberapa tahun terakhir ini menjadi semakin langka dan mahal di pasaran. Kekurangan jagung telah terjadi semenjak kurang lebih dua setengah dekade yang lalu, dimana Indonesia secara rutin terus mengimpornya. Pada tahun 2006, impor jagung mencapai 1,76 juta ton, tahun 2007 sebanyak 676,7 ribu ton, dan tahun 2008 sebanyak 170 ribu ton. ${ }^{4)}$

Dalam kondisi yang demikian ini, pemerintah melalui Departemen Pertanian memperkenalkan program Gema Palagung 2001 (Gerakan Mandiri padi, palawija, dan jagung untuk mencapai swasembada tahun 2001).5) Namun, upaya pengembangan komoditas jagung ini akan berhasil sesuai dengan yang diharapkan bila dikembangkan melalui cara budidaya yang tepat. Salah satu cara budidaya yang tepat adalah pemberian biomas pada tanah yang akan dapat meningkatkan kesuburan tanah adalah dengan cara budidaya lorong (alley cropping).

Cara budidaya lorong biasanya dilakukan di lahan kering dengan kemiringan antara 10 sampai dengan $20 \%$, dimana tanaman pangan ditanam diantara tanaman pagar yang berupa pohon, seperti Flemengia congesta. Secara periodik tanaman pagar ini dipangkas agar tanaman utama tidak ternaungi dan pada saat bersamaan menambahkan biomas ke dalam tanah. Dengan cara pengolahan tanah yang baik, pemberian kapur serta penambahan biomas dari tanaman pagar diharapkan tanah akan menjadi semakin produktif/ subur. Meningkatnya produktivitas tanah ditandai dengan: lebih tersedianya unsur hara tanah, peningkatan kapasitas tukar kation (KTK), memperbaiki struktur tanah, dan memperbaiki sifat biologi tanah. ${ }^{8)}$ Penelitian diharapkan secara efektif dapat diketahui pengaruh penggunaan biomass tanaman pagar Flemengia congesta terhadap produktivitas lahan khususnya untuk budidaya tanaman jagung.

\subsection{Tujuan Penelitian}

Penelitian ini bertujuan: (a). untuk mengetahui sejauh mana efektivitas pengaruh pemberian biomas maupun kombinasi biomas dan dolomit terhadap kesuburan/ produktivitas lahan. (b). untuk mengetahui tingkat dosis biomas maupun dolomit yang paling ekonomis dalam menyediakan unsurunsur hara yang cukup, khususnya untuk tanaman jagung.

\section{BAHAN DAN ALAT}

Bahan yang dipergunakan dalam penelitian ini adalah: (a). tiga sampel tanah yang masing-masing diambil pada lahan sebelum dan sesudah penerapan sistem budidaya lorong, (b). bahan untuk perlakuan (treatment) adalah biomas dari hasil pangkasan dahan dan ranting tanaman pagar Flemengia congesta dan dolomit, dan (c). hasil panen tanaman jagung (dalam bentuk biji kering) selama tiga musim tanam yang diambil dari plot masing-masing perlakuan. Adapun alat yang dipergunakan adalah timbangan untuk menimbang biomas, dolomit, dan hasil panen jagung.

\section{METODE PENELITIAN}

\subsection{Lokasi dan Waktu Penelitian}

Penelitian dilaksanakan di Proyek Transmigrasi Kuro Tidur Unit VIII, Desa Wonoharjo, Kecamatan Lais, Kabupaten Bengkulu Utara, Bengkulu. Penelitian ini dilakukan dalam tiga musim tanam, yaitu: pada Musim Tanam I (Pebruari sampai dengan Mei 2003), Musim Tanam II (Oktober 2003 sampai dengan Januari 2004), dan Musim Tanam III (Pebruari 2004 sampai dengan Mei 2004). Parameter yang diamati adalah produksi jagung dalam bentuk biji kering pada masing-masing plot perlakuan. Adapun kondisi tanah sebelum pelaksanaan penelitian relatif kurang subur yang dideskripsikan pada Tabel 1. 


\subsection{Rancangan Percobaan dan Perlakuan}

Rancangan percobaan yang digunakan adalah Rancangan Acak Lengkap (Complete Randomized Design) dengan empat perlakuan dan tiga ulangan. Perlakuan dalam penelitian ini adalah sebagai berikut: Perlakuan $\mathrm{A}=$ Kontrol, tanpa pemberian biomas maupun kapur. Perlakuan $\mathrm{B}=$ menggunakan biomas 5 ton/ha dan kapur 0 ton/ha. Perlakuan $\mathrm{C}=$ menggunakan biomas 5 ton/ha dan kapur 2,5 ton/ha. Perlakuan D $=$ menggunakan biomas 10 ton/ha dan kapur 2,5 ton/ha. Semua plot perlakuan diberi pupuk yang sama dengan dosis yaitu: 100 $\mathrm{kg} \mathrm{Urea/ha,} 100 \mathrm{~kg} \mathrm{TSP} / \mathrm{ha}$, dan $100 \mathrm{~kg} \mathrm{KCl} /$ ha. Luas setiap plot perlakuan adalah 100 $\mathrm{m}^{2}$, sehingga dengan empat perlakuan dan tiga ulangan diperlukan total luas $1.200 \mathrm{~m}^{2}$. Secara garis besar gambar plot percobaan adalah sebagai berikut:

\begin{tabular}{|c|c|c|c|c|}
\hline U-1 & A & D & C & B \\
\hline U-2 & D & C & B & A \\
\hline U-3 & B & A & D & C \\
\hline
\end{tabular}

Keterangan: U-1: ulangan 1, U-2: ulangan 2, U-3: ulangan 3.

\subsection{Analisis Data}

Analisis data untuk mengetahui adanya perbedaan antar perlakuan dilakukan dengan Analisis Sidik Ragam Satu Arah (One Way Analysis of Variance) dan untuk mengetahui tingkat pengaruh perlakuan biomas maupun kapur dilakukan dengan Analisis Regresi dan Korelasi.

\section{HASIL PENELITIAN DAN PEMBAHASAN}

Hasil analisis terhadap sampel tanah sebelum dilaksanakannya budidaya lorong menunjukkan bahwa reaksi tanahnya sangat asam, dengan $\mathrm{pH}=+4,25$, miskin unsur hara, seperti: kalium $(\mathrm{K})$ dengan kadar rata-rata $0,28 \mathrm{me} / 100 \mathrm{mg}$ (kadar sedang antara 0,40-0-0,50 me/ 100mg), kalsium (Ca) dengan kadar rata-rata $3,59 \mathrm{me} / 100 \mathrm{mg}$ (kadar sedang antara 6,00-10,00 me/100mg), magnesium $(\mathrm{Mg})$ dengan kadar rata-rata 0,66 me/100mg (kadar sedang antara 1,10-1,30 $\mathrm{me} / 100 \mathrm{mg}$ ), dan natrium ( $\mathrm{Na}$ ) dengan kadar $0,26 \mathrm{me} / 100 \mathrm{mg}$ (kadar sedang antara 0,30$0,70 \mathrm{me} / 100 \mathrm{mg}$ ). Sedangkan nilai Kapasitas Tukar Kation (KTK) rendah, rata-rata 17,3 me/100mg (nilai sedang antara 18,0-24,0 me/100mg). ${ }^{1)}$ Keadaan seperti ini adalah merupakan sifat umum tanah podzolik di Indonesia. Hal ini merupakan petunjuk bahwa perlu adanya usaha untuk meningkatkan produktivitas tanah dengan cara pengapuran dan pemberian biomas. Hasil analisis kimia tanah sebelum dan sesudah diterapkannya sistem budidaya lorong terutama dengan adanya pemberian kapur dan biomas dapat dilihat pada Tabel 1 .

Secara umum hasil analisis contoh tanah sebelum dan sesudah penerapan budidaya lorong menunjukkan adanya kecenderungan bahwa: semakin besar dosis pemberian kapur dan biomas akan semakin besar pula perbaikan sifat kimia tanah yang ditandai dengan: (a). adanya kecenderungan terhadap peningkatan $\mathrm{pH}$ tanah, ketersediaan unsur-unsur hara tanah: $\mathrm{K}, \mathrm{Na}, \mathrm{Ca}, \mathrm{Mg}$, dan KTK tanah, dan (b). adanya kecenderungan menurunnya ketersediaan unsur Al yang pada tingkat konsentrasi tertentu akan meracuni tanaman. Menurunnya ketersediaan unsur Al ini kemungkinan disebabkan karena terbentuknya khelat sebagai akibat dari adanya penambahan biomas. ${ }^{9)}$ 
Tabel 1. Hasil Analisis Contoh Tanah Sebelum dan Sesudah Penerapan Budidaya Lorong

\begin{tabular}{|c|c|c|c|c|c|c|c|c|c|c|c|c|c|c|}
\hline \multirow{3}{*}{$\begin{array}{l}\text { Per- } \\
\text { laku- } \\
\text { an }\end{array}$} & \multicolumn{2}{|c|}{$\mathrm{pH}$} & \multicolumn{2}{|c|}{ KTK } & \multicolumn{2}{|c|}{$\mathrm{Al}$} & \multicolumn{2}{|c|}{$\mathrm{K}$} & \multicolumn{2}{|c|}{$\mathrm{Na}$} & \multicolumn{2}{|c|}{$\mathrm{Ca}$} & \multicolumn{2}{|c|}{$\mathrm{Mg}$} \\
\hline & \multicolumn{2}{|c|}{$\left(\mathrm{H}_{2} \mathrm{O}\right)$} & \multicolumn{2}{|c|}{ (me/100 mg) } & \multicolumn{2}{|c|}{$\begin{array}{c}(\mathrm{me} / 100 \\
\mathrm{mg})\end{array}$} & \multicolumn{2}{|c|}{$\begin{array}{c}(\mathrm{me} / 100 \\
\mathrm{mg})\end{array}$} & \multicolumn{2}{|c|}{$\begin{array}{c}(\mathrm{me} / 100 \\
\mathrm{mg})\end{array}$} & \multicolumn{2}{|c|}{$\begin{array}{c}(\mathrm{me} / 100 \\
\mathrm{mg})\end{array}$} & \multicolumn{2}{|c|}{$\begin{array}{c}(\mathrm{me} / 100 \\
\mathrm{mg})\end{array}$} \\
\hline & Sbl & Ssd & Sbl & Ssd & Sbl & Ssd & Sbl & Ssd & Sbl & Ssd & Sbl & Ssd & Sbl & Ssd \\
\hline A & 4,00 & 5,40 & 15,50 & 17,90 & 1,86 & 0,50 & 0,31 & 0,54 & 0,26 & 0,43 & 3,38 & 6,06 & 0,68 & 1,14 \\
\hline$B$ & 4,10 & 5,40 & 16,50 & 19,50 & 2,55 & 0,52 & 0,25 & 0,52 & 0,25 & 0,43 & 2,41 & 6,73 & 0,49 & 1,18 \\
\hline C & 4,70 & 6,20 & 18,60 & 19,80 & 1,82 & 0,77 & 0,33 & 0,77 & 0,30 & 0,52 & 5,40 & 8,99 & 0,96 & 1,16 \\
\hline D & 4,20 & 5,30 & 18,60 & 20,80 & 2,43 & 0,62 & 0,23 & 0,62 & 0,24 & 0,52 & 3,18 & 5,82 & 0,50 & 1,93 \\
\hline $\begin{array}{l}\text { Rata } \\
\text { rata }\end{array}$ & 4,25 & & 17,3 & & 2,18 & & 0,28 & & 0,26 & & 3,59 & & 0,66 & \\
\hline
\end{tabular}

Keterangan: Analisis tanah dilakukan di Laboratorium Jurusan IImu-ilmu Tanah, Fakultas Pertanian Institut Pertanian Bogor (IPB), Bogor.
$\mathrm{A}=$ kontrol, tanpa pemberian biomas maupun kapur.
$\mathrm{B}=$ menggunakan biomas 5 ton/ha dan kapur 0 ton/ha.
C = menggunakan biomas 5 ton/ha dan kapur 2,5 ton/ha.
D = menggunakan biomas 10 ton/ha dan kapur 2,5 ton/ha.
$\mathrm{Sbl}=$ sebelum penerapan budidaya lorong.
Ssd $=$ sesudah penerapan budidaya lorong .

Hasil penelitian menunjukkan bahwa pengaruh pemberian kapur dengan dosis sebesar 2,5 ton/ha pada tingkat pemberian biomas yang sama, yaitu 5,0 ton/ha (lihat pada perlakuan B dan C, Tabel 2) akan meningkatkan produksi jagung kering dari $37,433 \mathrm{kw} / \mathrm{ha}$ menjadi $47,611 \mathrm{kw} / \mathrm{ha}$ atau naik $27,19 \%$. Meningkatnya produktivitas tanah ini kemungkinan disebabkan oleh lebih tersedianya unsur hara tanah, peningkatan KTK, memperbaiki sifat biologi tanah dan memperbaiki struktur tanah. ${ }^{8)}$

Pengaruh pemberian kapur dan biomas yang dilakukan secara bersama sama menunjukkan bahwa: (a). Pengaruh pemberian kapur 2,5 ton/ha dan biomas 5,0 ton/ha (lihat perlakuan A dan C, Tabel 2) akan meningkatkan hasil jagung dari 22,256 kw/ ha menjadi $47,611 \mathrm{kw} / \mathrm{ha}$ atau naik 113,92 $\%$, (b). Pengaruh pemberian kapur 2,5 ton/ ha dan biomas 10,0 ton/ha (lihat perlakuan A dan D, Tabel 2) akan meningkatkan hasil jagung dari $22,256 \mathrm{kw} / \mathrm{ha}$ menjadi 50,789 $\mathrm{kw} / \mathrm{ha}$ atau naik $128,20 \%$.

Lebih lanjut, pengaruh pemberian biomas ini diterangkan sebagai berikut: Pengaruh pemberian biomas dengan tanpa pemberian kapur (lihat perlakuan A dan $B$, Tabel 2). Pengaruh pemberian biomas dengan dosis sebesar 5,0 ton/ha dapat menaikkan hasil jagung dari 22,256 kw/ ha menjadi $37,433 \mathrm{kw} / \mathrm{ha}$ atau naik 68,19 $\%$. Hal ini mengacu pada hasil penelitian yang dilakukan oleh Wynne Thurne bahwa biomas mampu meningkatkan hasil jagung secara nyata karena biomas yang sudah terdekomposisi akan mengikat aluminium (Al) tanah menjadi senyawa khelat yang kompleks sehingga tidak meracuni tanaman. ${ }^{9}$ Dampak dari kasus ini adalah mengurangi kebutuhan kapur dalam jumlah banyak, dimana fungsi kapur akan menetralkan tanah yang bisa digantikan dengan biomas yang diperoleh dari hasil pangkasan tanaman pagar. 
Tabel 2. Rata-rata Produksi Jagung dalam Budidaya Lorong (kw/ha, biji kering)

\begin{tabular}{|c|l|l|l|l|l|l|l|l|l|l|}
\hline \multirow{2}{*}{ Perlakuan } & \multicolumn{7}{|c|}{ Musim Tanam / Ulangan } & \multirow{2}{*}{ Rata-rata } \\
\cline { 2 - 11 } & \multicolumn{3}{|c|}{ Musim Tanam I } & \multicolumn{3}{c|}{ Musim Tanam II } & \multicolumn{3}{c|}{ Musim Tanam II } & \\
\hline & 1 & 2 & 3 & 1 & 2 & 3 & 1 & 2 & 3 & \\
\hline A & 23,2 & 21,8 & 22,3 & 22,8 & 22,1 & 22,7 & 23,4 & 20,6 & 21,4 & 22,256 \\
\hline B & 35,8 & 37,4 & 38,2 & 37,9 & 37,4 & 37,6 & 38,2 & 36,8 & 37,6 & 37,433 \\
\hline C & 47,9 & 48,1 & 48,3 & 46,9 & 46,9 & 47,7 & 47,9 & 47,3 & 47,5 & 47,611 \\
\hline D & 51,2 & 52,1 & 50,8 & 50,6 & 49,7 & 51,1 & 51,2 & 49,7 & 50,7 & 50,789 \\
\hline
\end{tabular}

Pemberian biomas dengan dosis pemberian dolomit sebesar 2,5 ton/ha (lihat perlakuan $\mathrm{C}$ dan $\mathrm{D}$, Tabel 2). Pengaruh penambahan dosis biomas dari 5 ton/ha menjadi 10 ton/ha akan dapat meningkatkan hasil jagung dari 47,611 kw/ha menjadi 50,789 $\mathrm{kw} / \mathrm{ha}$ atau naik $6,67 \%$. Secara ringkas matrik persentase peningkatan produktivitas lahan melalui indikator peningkatan produksi jagung dideskripsikan pada Tabel 3. Lebih lanjut, dari hasil Analisis Sidik Ragam menunjukkan bahwa ada perbedaan yang nyata antara perlakuan $A, B, C$, dan D.

Hasil analisis ekonomi terhadap empat perlakuan tersebut diterangkan sebagai berikut:

a. Perbandingan antara perlakuan A dan
B. Dalam hal ini, perlakuan B yang dilakukan dengan menggunakan biomas sebanyak 5,0 ton/ha dari hasil pangkasan tanaman pagar tanpa perlakuan dolomit, akan mampu meningkatkan rata-rata produksi jagung menjadi sebesar 37,433 kw/ha (dalam bentuk biji kering, lihat Tabel 2 dan 3). Dengan perhitungan bahwa harga jagung = Rp. 500,-/kg dan harga biomas dari hasil pangkasan tanaman pagar $=$ Rp. 40,-/kg (merupakan ratarata biaya produksi tanaman pagar dibagi dengan produksi biomas) maka perlakuan $\mathrm{B}$ tersebut mampu memberikan tambahan pendapatan pada petani sebesar Rp. 558.850,(lihat Tabel 4).

Tabel 3. Besar Peningkatan Produksi Jagung dengan Perlakuan Biomas dan Dolomit

\begin{tabular}{|l|l|l|l|l|l|l|l|l|}
\hline & \multicolumn{2}{|c|}{ A } & \multicolumn{2}{c|}{ B } & \multicolumn{2}{c|}{ C } & \multicolumn{2}{c|}{ D } \\
\hline Perlakuan & $k w / h a$ & $\%$ & $k w / h a$ & $\%$ & $k w / h a$ & $\%$ & $k w / h a$ & $\%$ \\
\hline A & 0,000 & 0,00 & & & & & & \\
\hline B & 15,177 & 68,19 & 0,000 & 0,00 & & & & \\
\hline C & 25,355 & 113,92 & 10,178 & 27,19 & 0,000 & 0,00 & & \\
\hline D & 28,533 & 128,20 & 13,356 & 35,68 & 3,178 & 6,67 & 0,000 & 0,00 \\
\hline
\end{tabular}


Tabel 4. Biaya Sarana Produksi, Pendapatan, dan Keuntungan dalam Budidaya Jagung (per ha) Menurut Perlakuan

\begin{tabular}{|c|c|c|c|c|c|c|c|}
\hline \multirow{2}{*}{\multicolumn{2}{|c|}{ Perlakuan }} & \multicolumn{2}{|c|}{ Sarana Produksi } & \multicolumn{2}{|c|}{ Hasil Panen } & \multirow{2}{*}{$\begin{array}{l}\text { Keuntungan } \\
\text { (Rp/ha) }\end{array}$} & \multirow{2}{*}{$\begin{array}{c}\text { Selisih } \\
\text { Keuntungan } \\
\text { dg perlak. A } \\
\text { (Rp/ha) }\end{array}$} \\
\hline & & $\begin{array}{l}\text { Jumlah } \\
\text { (kg/ha) }\end{array}$ & $\begin{array}{l}\text { Biaya } \\
\text { (Rp/ha) }\end{array}$ & $\begin{array}{l}\text { Jumlah } \\
\text { (kw/ha) }\end{array}$ & $\begin{array}{l}\text { Pendapatan } \\
\text { (Rp/ha) }\end{array}$ & & \\
\hline & (1) & (2) & (3) & (4) & (5) & $\begin{array}{c}(6)=(5)- \\
(3)\end{array}$ & (7) \\
\hline & Biomas & 0 & 0 & & & & \\
\hline \multirow[t]{3}{*}{$A$} & Dolomit & 0 & 0 & & & & \\
\hline & Total & & 0 & 22,256 & 1.112 .800 & 1.112 .800 & 0 \\
\hline & Biomas & 5.000 & 200.000 & & & & \\
\hline \multirow[t]{3}{*}{$B$} & Dolomit & 0 & 0 & & & & \\
\hline & Total & & 200.000 & 37,433 & 1.871 .650 & 1.671 .650 & 558.850 \\
\hline & Biomas & 5.000 & 200.000 & & & & \\
\hline \multirow[t]{3}{*}{$\mathrm{C}$} & Dolomit & 2.500 & 750.000 & & & & \\
\hline & Total & & 950.000 & 47,611 & 2.380 .550 & 1.430 .550 & 317.750 \\
\hline & Biomas & 10.000 & 400.000 & & & & \\
\hline \multirow[t]{2}{*}{ D } & Dolomit & 2.500 & 750.000 & & & & \\
\hline & Total & & 1.150 .000 & 50,789 & 2.539 .450 & 1.389 .450 & 276.650 \\
\hline
\end{tabular}

b. Perbandingan antara perlakuan $\mathrm{A}$ dan C. Perlakuan $\mathrm{C}$ dalam penelitian ini, yang dilakukan dengan menggunakan 5 ton biomas dan 2,5 ton dolomit, akan mampu meningkatkan rata-rata produksi jagung menjadi sebesar 47,611 kw/ha (lihat Tabel 2 dan 3). Dengan perhitungan bahwa harga jagung $=$ Rp. 500,-/kg, harga biomas dari hasil pangkasan tanaman pagar $=$ Rp. 40,-/kg dan harga dolomit = Rp. $300,-/ \mathrm{kg}$, maka perlakuan C tersebut mampu memberikan tambahan pendapatan pada petani sebesar Rp. 317.750,- (lihat Tabel 4).

c. Perbandingan antara perlakuan $A$ dan D. Perlakuan $D$ dalam penelitian ini, yaitu dengan menggunakan 10 ton biomas dan 2,5 ton dolomit, akan mampu meningkatkan rata-rata produksi jagung menjadi sebesar 50,789 kw/ha (lihat Tabel 2 dan 3).
Dengan perhitungan bahwa harga jagung $=$ Rp. 500,-/kg, harga biomas dari hasil pangkasan tanaman pagar $=$ Rp. 40,-/kg, dan harga dolomit $=$ Rp. $300,-/ \mathrm{kg}$, maka perlakuan $\mathrm{D}$ tersebut hanya mampu memberikan tambahan pendapatan pada petani sebesar Rp. 276.650,- (lihat Tabel 4).

Oleh karena itu dari hasil analisis ekonominya menunjukkan bahwa perlakuan $B$, yaitu pemberian biomas dari hasil pangkasan tanaman pagar Flemengia congesta dengan dosis sebesar 5 ton/ha merupakan perlakuan yang paling ekonomis/ menguntungkan.

Hasil Analisis Regresi untuk mengetahui tingkat pengaruh pemberian biomas dan kapur dolomit terhadap produksi jagung dalam penelitian ini dideskripsikan dalam persamaan regresi berikut ini: $Y=$ $34,26+0,063 \mathrm{X} 1+0,41 \mathrm{X} 2(\mathrm{Y}=$ produksi jagung, $\mathrm{X} 1=$ biomas, dan $\mathrm{X} 2=$ dolomit). Dari 
persamaan regresi tersebut diungkapkan pula bahwa pemberian biomas dan dolomit ini secara bersama sama/kombinasi mempunyai pengaruh yang nyata terhadap produksi jagung. Nilai koefisien korelasi antara variabel produksi jagung dan variabel biomas adalah 0,679 , sedangkan nilai koefisien korelasi antara variabel produksi jagung dan variabel dolomit adalah 0,967.

\section{KESIMPULAN}

Kombinasi penggunaan biomas dari hasil pangkasan daun dan ranting tanaman pagar Flemengia congesta dan kapur dolomit berpotensi secara signifikan dalam penyuburan/peningkatan produktivitas lahan, khususnya dalam budidaya tanaman jagung. Oleh karena itu cara budidaya lorong dengan menggunakan tanaman pagar sebagai penghasil biomas yang relatif cepat, murah, dan mudah ini merupakan teknologi tepat yang sangat berguna bagi petani khususnya dalam budidaya tanaman jagung di lahan kering.

Pengaruh pemberian biomas yang dikombinasikan dengan kapur menunjukkan adanya kecenderungan bahwa pemberian pada dosis biomas dan kapur yang semakin tinggi akan semakin tinggi pula produktivitasnya. Peranan dolomit dalam penyuburan lahan ternyata lebih besar dibandingkan dengan peranan biomas dari hasil pangkasan tanaman pagar. Namun, karena harga dolomit mahal, maka secara ekonomis pemberian biomas dengan dosis 5 ton/ha dengan tanpa pemberian dolomit (perlakuan B) merupakan dosis yang paling menguntungkan dalam budidaya tanaman jagung khususnya di lahan jenis podzolik.

\section{DAFTAR PUSTAKA}

1. Anonimous 1974. Penelitian dan Pemetaan Tanah Areal Pabrik Gula Kanigoro, Madiun. Lembaga Penelitian Tanah. Bogor.

2. 1988. Monitoring and Improving Agrilime Use in
Transmigration Area (continuation). Cooperation between PSP2DT Direktorat Jenderal Pertanian Tanaman Pangan, Departemen Pertanian dan Fakultas Pertanian Institut Pertanian Bogor (IPB).

3.

Pelaksanaan Kegiatan Demonstrasi Usahatani Konservasi Daerah Transmigrasi. Dinas Pertanian Tanaman Pangan Kabupaten Daerah Tingkat II Bengkulu Utara.

4. 2009. Kadin Ragukan Data Produksi Jagung BPS http:// news.id. finroll.com/bisnis/ agriculture/10930-kadin. ragukandata-produksi-jagung-bps. html.

5. Mulyono. D. 2005. Pengolahan Limbah Jagung Untuk Pupuk Organik di Propinsi Gorontalo. Laporan Teknis. BPP Teknologi. Jakarta

6. Notohadipoero. A.R.S. et al. 1979. Pengantar IImu Tanah. Departemen IImu Tanah, Fakultas Pertanian Universitas Gadjah Mada, Yogyakarta.

7. Soepardi. G. 1979. Sifat dan Ciri Tanah. Jilid I dan II. Institut Pertanian Bogor.

8. Soepardi. G. et al. 1988. Budidaya Lorong. Teknologi Bermasukan Terjangkau Petani Sebagai Pilihan Berusahatani Konservatif. Institut Pertanian Bogor.

9. Wigena. I.G.P. dan J.S. Adiningsih. 1987. Pengaruh Pengapuran dan Residunya Serta Penambahan Biomas Terhadap Hasil Kedelai Pada Tanah Typic Haplortox Kuamang Kuning. Prosiding Pertemuan Teknis Penelitian Tanah. Pusat Penelitian Tanah, Badan Litbang Pertanian, Departemen Pertanian. 